\title{
Contextual Variables as Pronouns
}

\author{
Luisa Martí \\ University of the Witwatersrand
}

\section{Introduction}

In this paper I pursue the hypothesis that contextual variables of the kind associated with quantificational expressions like every, most or usually, abbreviated as $\mathrm{C}$ from now on, are covert pronominal items. An important advantage that this hypothesis offers is that, if true, then the grammatical tools needed to explain properties of pronouns can be used to explain properties of $\mathrm{C}$; i.e., no new machinery needs to be introduced into the grammar to deal with $\mathrm{C}$.

If $\mathrm{C}$ is a pronoun, then we expect the behavior of $\mathrm{C}$ to be like the behavior of pronouns. What I do in this talk is show that the behavior of bound $\mathrm{C}$ is indeed like the behavior of bound pronouns ${ }^{1}$. In particular, I show that $\mathrm{C}$ is subject to Weak Crossover (WCO).

The organization of the talk is as follows. In $\S 2$, I lay out my assumptions about $\mathrm{C}$ and I discuss arguments against two alternative analyses of the data. In $\S 3$, I show that, just like pronouns, $\mathrm{C}$ is subject to $\mathrm{WCO}$ in two languages, Mandarin Chinese and English. I also show, importantly, that exceptions to WCO that obtain with pronouns in languages like English obtain with $\mathrm{C}$ as well, thus making the case for the pronominal status of $\mathrm{C}$ stronger. Brief notes on how the data I present here was collected are included in this section as well. In $\S 4$ I discuss some theoretical consequences and issues that arise from the data and I conclude the paper in $\S 5$.

\section{2. $\mathrm{C}$}

\subsection{Assumptions about $C$}

This paper is about the $\mathrm{C}$ that in the analyses in e.g., von Fintel, 1994 \& 1995 and Westerståhl, 1985 is associated with quantificational expressions like every or always. To see what $\mathrm{C}$ does, consider the example in (1):

(1) [Speaker A is relating to Speaker B the experiences of last night, when A and some of his students went out for a pizza]

A: Everybody ${ }_{C}$ had a great time $\quad$ (von Fintel, 1994: 28 \& 1995: 163)

Speaker A in (1) does not intend to convey the idea that everybody, literally, had a great time. Rather, the quantification is over a restricted set of people, those that went out for a pizza last night with A. Positing a contextual variable in the lexical entry of the quantified determiner every is one way to capture this context 
dependency ${ }^{2}$. A common notational device adopted by this approach is a subscript ' $\mathrm{C}$ ', as shown in $(1 \mathrm{~A})$.

It has been noted in the literature that $\mathrm{C}$ can be bound as well as free. Heim, 1991 and von Fintel, 1994, 1995 note the example in (2):

\section{Only one class was so bad that no $\mathrm{C}_{\mathrm{C}}$ student passed the exam}

What is at stake here is the $\mathrm{C}$ of no. This variable is bound by the upstairs quantificational expression, only one class, to result in a reading that can be paraphrased as "only one class $\mathrm{x}$ was such that $\mathrm{x}$ was so bad that no student in $\mathrm{x}$ passed the exam". This reading suggests that $\mathrm{C}$ is of a more complex nature than just a simple variable. von Fintel assumes that it is composed of a functional variable and an argumental variable (cf. Stanley, 2000 \& 2002; Stanley and Szabo, 2000; Chierchia, 1993 and Engdahl, 1986 on wh-traces; Jacobson, 2000 on pay-check pronouns; Heim, 1990 and Elbourne, 2002 on donkey pronouns):

$$
\mathrm{C}=\mathrm{f}_{\mathrm{i}}\left(\mathrm{x}_{\mathrm{j}}\right), \mathrm{i}, \mathrm{j} \in \mathbb{N}
$$

The analysis of (2) is then as in (4):

$$
\text { [only one class] }]_{1} \text { was so bad that } \operatorname{no}_{f_{2}\left(x_{1}\right)} \text { student passed the exam]] }
$$

What gets bound in this analysis by the upstairs quantificational expression is the argumental variable of $\mathrm{C}$. The functional variable stays free and is assigned a salient function as its value (of type $\langle\mathrm{e},<\mathrm{e}, \mathrm{t}>>$; a function that takes a class and gives back the set of individuals in that class). The functional variable takes the argumental variable as its argument and results in a set of individuals, which is intersected with the noun student via Predicate Modification.

I follow von Fintel in the idea that $\mathrm{C}$ has a function-argument internal composition. Given this, let me make the hypothesis to be defended in this paper more fine-grained, by claiming that the argumental variable of $\mathrm{C}$ is a covert pronominal item. This paper then shows that the argumental variable of $\mathrm{C}$, when bound, behaves like bound pronouns in that it is subject to the same principles ${ }^{3}$. Of course, the hypothesis that the functional variable of $\mathrm{C}$ is a covert pronominal item should be equally considered, but I won't do that here ${ }^{4,5}$.

A second assumption I make in this paper is that $C$ is present in the syntax in the manner shown in (5), with the denotation of $n o$ as in (6):

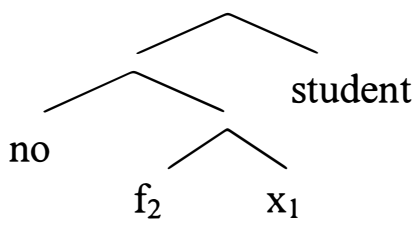

$$
[[\text { no }]]^{\mathrm{g}}=\lambda \mathrm{C} \lambda \mathrm{k} \lambda \mathrm{h}: \mathrm{C}, \mathrm{k}, \mathrm{h} \in \mathrm{D}_{<\mathrm{e}, \mathrm{t}>} .\{\mathrm{x}: \mathrm{C}(\mathrm{x})=1 \& \mathrm{k}(\mathrm{x})=1\} \cap\{\mathrm{x}: \mathrm{h}(\mathrm{x})=1\}=\varnothing
$$


This is an assumption that neither von Fintel nor Westerståhl make, and, even though it is made by other authors (see, e.g., Stanley, 2000 \& 2002), it is likely that not everybody will agree on the particular representation in (5). I come back to some of these issues in $\S 2.2$ and in $\S 4$.

\subsection{Against analyses where nouns are responsible for bound readings}

Before presenting the data that shows that $\mathrm{C}$ is subject to $\mathrm{WCO}$, it is first necessary to argue against the following two alternative analyses of the bound reading of (2).

In the first alternative analysis, what gets bound is an implicit variable introduced by relational nouns ${ }^{6}$ (see e.g., Barker and Dowty, 1992 for discussion of this variable). If relational nouns come with a variable of their own, then the bound reading described above for (2) might originate in the variable of student ${ }^{7}$, instead of in the variable of no. And hence (2) might not tell us anything about C.

Relational nouns, however, cannot be responsible for all bound readings: bound readings are available with non-relational nouns $((7))$ and with relational nouns whose potential implicit argument is filled ((9)). Consider first (7):

(7) The people in our neighborhood are affiliated with a number of different charities. For example, John belongs to "Children of the World", Susan to "Children of the World" and "We are the Children", Bill to "ActionAid", Stefan to "We are the children", "ActionAid" and "PeaceNow', and so on for the other fifteen neighbors. It is customary to donate money to charities before Christmas. This year, [most people $]_{1}$ have given money to $\left[\left[\right.\right.$ every $\left.\left[\mathrm{f}_{2} \mathrm{x}_{1}\right]\right]$ charity $]$.

The italicized sentence in (7) has a reading that can be paraphrased as "most people $\mathrm{x}$ have given money to every charity $\mathrm{x}$ is affiliated with". In my analysis, this a reading in which the argumental variable of $\mathrm{C}$ is bound. The functional variable of $\mathrm{C}$ gets assigned the value in (8):

$$
\lambda x \lambda y . x \text { is affiliated with } y
$$

Importantly, charity is not a relational noun ${ }^{8}$, so no variable introduced by a relational noun can be responsible for the bound reading of this sentence. Now consider (9):

(9) The business professors gathered in the faculty room. The meeting was about the companies with which the School of Business has close contacts. Several professors have had contact with several representatives from those companies lately. As it turns out, [every professor $]_{1}$ admires [[every $\left[\mathrm{f}_{2} \mathrm{x}_{1}\right]$ representative of Kodak $]$ 
The italicized sentence in (9) has a reading that can be paraphrased as "every professor $\mathrm{x}$ admires every representative of Kodak $\mathrm{x}$ has been in contact with". In my analysis, this is a bound reading of $\mathrm{C}$. The functional variable of $\mathrm{C}$ gets assigned the value in (10):

$$
\lambda \mathrm{x} \lambda \mathrm{y} . \mathrm{x} \text { has been in contact with } \mathrm{y}
$$

Importantly, the bound reading of this sentence cannot be traced to a variable associated with the relational noun representative, for that variable is filled by overt material, of Kodak'.

In the second alternative analysis, what gets bound is an implicit variable introduced by nouns generally, not just relational nouns, as proposed in e.g., Stanley, 2000, 2002.

A variable introduced by nouns, however, cannot be responsible for all bound readings, since bound readings are available with adverbs of quantification, where no noun can be blamed. Consider the example in (11):

(11) [Only one summer $]_{1}$ was so bad that, if it rained, I [always [ $\left.f_{2} x_{1}\right]$ missed the bus

(cf. Cooper, 1996 for similar examples)

(11) has a reading that can be paraphrased as "only one summer $\mathrm{x}$ was so bad that all situations in which it rained in $x$ are situations in which I missed the bus". In this reading, the functional variable of the $\mathrm{C}$ of always gets assigned the value in (12) in my analysis ${ }^{10}$ :

$$
\lambda x \lambda s . s<x
$$

Importantly, adverbs of quantification do not take nouns as arguments, so the variable of a noun cannot figure in the analysis of the bound reading of (11).

The conclusion that I draw from this discussion is that the bound readings of interest here are independent of (relational) nouns but dependent on the quantificational expression (whether it be a determiner quantifier like every or an adverb of quantification like always). More generally, the conclusion is that the context dependence of quantification is located in the quantifier, not in the noun that sometimes goes with the quantifier.

\section{Bound $\mathrm{C}=$ bound pronouns}

\section{1. $C$ and $W C O$}

The version of the principle of WCO that I assume here is that in Lasnik and Stowell, 1991, in (13): 
(13) In a configuration where a pronoun $\mathrm{P}$ and a trace $\mathrm{T}$ are both bound by a quantifier $\mathrm{Q}, \mathrm{T}$ must c-command $\mathrm{P}$

Other formulations of the principle are possible, of course (see, e.g., Chomsky, 1976; Jacobson, 2000; Koopman and Sportiche, 1983; Postal, 1971 and Wasow, 1972). I work here with (13), though ${ }^{11}$.

(13) is about the contrast between (14a) and (14b) and between (15a) and

(14) a. $\left[\mathrm{Who}_{1}\left[\mathrm{t}_{1}\right.\right.$ admires $\left[\mathrm{his}_{1}\right.$ boss $\left.\left.]\right]\right]$ ?

b. ${ }^{*}\left[\mathrm{Who}_{1}\right.$ [does $\left[\right.$ his $_{1}$ boss] admire $\left.\left.\mathrm{t}_{1}\right]\right]$ ?

(15) a. [Everyone ${ }_{1}\left[\mathrm{t}_{1}\right.$ admires [his $\mathrm{H}_{1}$ boss $\left.\left.]\right]\right]$

b. ${ }^{*}\left[\right.$ everyone $_{1}\left[\left[\right.\right.$ his $_{1}$ boss $]$ admires $\left.\left.\mathrm{t}_{1}\right]\right]$ (i.e., his boss admires everyone)

A bound reading of the pronoun his is available in (14a) though not in (14b). And the trace of who c-commands the pronoun in the former and not in the latter. The same observation, but with everyone, is made about (15) ((15b) is obtained after $\mathrm{QR}$ of everyone).

$\mathrm{C}$ is subject to WCO, just as pronouns are. Consider first (16):

(16) The business professors gathered in the faculty room. The meeting was about the companies with which the School of Business has close contacts. Several professors are in contact with several representatives from those companies. One of the professors asked...

$[\mathrm{Who}]_{1} \mathrm{t}_{1}$ admires $\left[\left[\right.\right.$ every $\left.\left[\mathrm{f}_{2} \mathrm{x}_{1}\right]\right]$ representative of Kodak]?

The question in (16) has a reading that can be paraphrased as "which person $\mathrm{x}$ is such that $\mathrm{x}$ admires every representative of Kodak $\mathrm{x}$ has been in contact with?", where the value that the functional variable of $\mathrm{C}$ gets assigned is as in (17):

$(=(10)) \lambda x \lambda y . x$ has been in contact with $\mathrm{y}$

That is, the question asks for the person such that that person admires every representative of Kodak that person has been in contact with. Answering this question with "Peter" would mean that Peter is the person who admired every representative of Kodak he himself has been in contact with. Peter may not admire representatives of Kodak he himself hasn't been in contact with at all. This is a reading in which the $\mathrm{C}$ of every is bound.

This is in contrast with (18), where the context preceding the question is the same as in (16):

[same context as (16)]

$*$ [Who $]_{1}$ does $\left[\left[\right.\right.$ every $\left[f_{2} x_{1}\right]$ representative of Kodak] admire $t_{1}$ ? 
As opposed to the question in (16), the question in (18) does not have a reading where the $\mathrm{C}$ of every is bound. That is, the question cannot ask, "which person $\mathrm{x}$ is such that every representative of Kodak $\mathrm{x}$ has been in contact with admires $\mathrm{x}$ ?". Rather, it must be about professors liked by every representative of Kodak in some contextually salient set (for example, in the set of representatives of Kodak the School of Business has been in contact with).

This is the kind of behavior we expect if $\mathrm{C}$ is a pronoun: if $\mathrm{C}$ is a pronoun, $\mathrm{C}$ should be subject to the same constraints that pronouns are subject to. The examples in (16) and (18) show that this is the case with respect to WCO.

Notice, incidentally, that the bound readings of (16) and (18) are not functional/pair-list readings of the kind Chierchia, 1993 and Engdahl, 1986, among others, worry about. There is an easy way of seeing this: (16) has a bound reading of $\mathrm{C}$ but no pair-list or functional readings, whereas (18) has pair-list and functional readings but no bound reading of $\mathrm{C}$.

$\mathrm{C}$ is subject to WCO in other languages as well, just as pronouns in those languages are subject to WCO. (19)-(22) make the case for Mandarin Chinese:

a. Shei ${ }_{1}$ kanjian-le ta ${ }_{1}$ muqin?

Who see-Asp he mother

'Who saw his mother?'

b. ${ }^{*} \mathrm{Ta}_{1}$ muqin kanjian-le shei ${ }_{1}$ ?

he mother see-Asp who

'Who did his mother see?'

$($ Asp $=$ aspectual perfective marker $)$

(Higginbotham, 1980; Huang, 1982)

Regular pronouns like $t a$ 'he/his' in Chinese are subject to WCO: a bound reading of the pronoun is available in (19a) though not in (19b). Note that shei 'who moves only covertly in Chinese. Other than this, the English and the Chinese examples are parallel in the relevant respect.

Now consider the example in (20), where what gets bound is the argumental variable of the $\mathrm{C}$ of mei-men 'every' instead of a pronoun like ta:

(20) [The students in the physics department gathered in the lounge to discuss their choice of courses in the spring of 2001. At the end of the meeting, the president asked...]

Shei $i_{1}\left[\left[\right.\right.$ mei-men $\left.\left[f_{2} x_{1}\right]\right]$ kecheng] dou xihuan?

who every-CL course all like $\quad(\mathrm{CL}=$ classifier $)$

'Who liked every course?'

The question asked in (20) has a reading that can be paraphrased as "which person $\mathrm{x}$ is such that $\mathrm{x}$ liked every course $\mathrm{x}$ chose/took in the spring of 2001 ", where the value of the functional variable that stays free is as in (21):

$\lambda x \lambda y . x$ chose/took $y$ in the spring of 2001

That is, the president asks about the person who liked every course that the person himself/herself took in the spring of 2001, as opposed to asking about the person 
who liked every course in some contextually salient set, which would be the reading in which the $\mathrm{C}$ of mei-men 'every' remains free.

Notice, incidentally, that quantificational object NPs with dou 'all' in Chinese must appear preverbally, as noted in the literature (Lin, 1998).

(20) contrasts with (22):

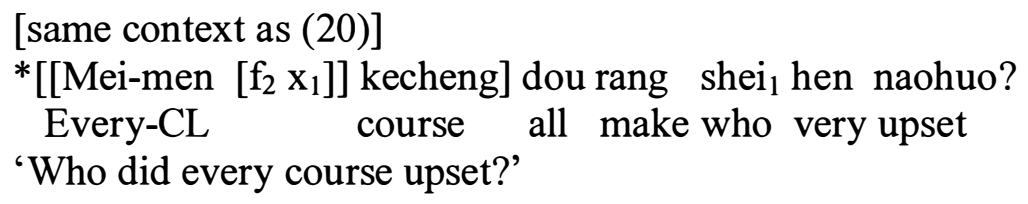

The context is the same as in (20). The question in (22), however, cannot have a reading in which the argumental variable of the $\mathrm{C}$ of mei-men 'every' is bound. That is, the question does not have a reading that can be paraphrased as "which person $\mathrm{x}$ is such that every course that $\mathrm{x}$ chose/took in the spring of 2001 upset $\mathrm{x}$ ". The contrast between (20) and (22) is expected if $\mathrm{C}$ is a pronoun subject to pronoun constraints: shei 'who' c-commands C in (20), but not in (22) (after LF movement of shei).

The behavior of bound $\mathrm{C}$ is then just like the behavior of bound pronouns, at least with respect to one of the constraints on binding, WCO, and in two languages, English and Chinese.

\subsection{Cross-linguistic variation in the behavior of $C$}

Considering the behavior of languages like Chinese with respect to binding of variables is important because the distribution of bound variables is more restricted in this language than in others like English: whereas English possessive binders (i.e., whose) can bind pronouns (at least for some speakers), Chinese possessives cannot. Given the hypothesis pursued in this paper, the prediction is made that possessives can bind $\mathrm{C}$ in English but not in Chinese. The prediction is indeed confirmed.

Higginbotham, 1980 notes that possessives, like shei de 'whose' or meige-ren de 'everybody's' cannot bind pronouns in Chinese:

*Shei ${ }_{1}$ de muqin kanjian-le ta ${ }_{1}$ ? who mother see-Asp him $(d e=$ possessive marker $)$

'Whose mother saw him?'

*Mei-ge-ren 1 de muqin dou shuo wo xihuan $\operatorname{ta}_{1}$ every-CL-man mother all say I like him 'Everybody's mother said that I liked him'

Neither (23) nor (24) have readings in which the pronoun ta is bound by shei or mei-ge-ren; these sentences only admit a free interpretation of the pronouns. 
Significantly, the same state of affairs obtains with C. In (25), the context preceding the question is the same as it was in example (20):

[same context as (20)]

*Shei ${ }_{1}$ de muqin [[mei-men $\left.\left[f_{2} x_{1}\right]\right]$ kecheng] dou fu-le qian? who mother every-CL course all pay-ASP money 'Whose mother paid for every course?'

This question cannot be interpreted as "which person $\mathrm{x}$ is such that $\mathrm{x}$ 's mother paid for every course that x chose/took?". The only interpretation it can have is one in which it asks for the person whose mother paid for every course in some contextually salient set, e.g., in the set of courses offered by the physics department in the spring of 2001. This is so even though the interpretation in which the $\mathrm{C}$ of mei-men 'every' is bound is more plausible (i.e., it is more plausible for people to pay for courses that their own children have taken than it is for people to pay for courses that their own children might not have taken).

In this respect, Chinese is well-behaved with respect to WCO ((13)), since WCO prohibits binding by possessives (their trace does not c-command the pronoun).

In English, however, many speakers allow binding by whose or everyone's. Consider the examples in (26) and (27):

[Every man $]_{1}$ 's/everyone 1 's mother loves him 1

(e.g., Jacobson, 2000; Safir, 1996)

Whose $_{1}$ picture incriminated his ${ }_{1}$ mother?

(Safir, 1996)

In this English does not obey WCO. We will see further exceptions to WCO in English in §3.3, but first let me show that the expectation that possessives be able to bind $\mathrm{C}$ in English is fulfilled. In the example in (28), the context preceding the question is the same as in (20); the example is the English equivalent of the Chinese in (22):

[same context as (20)]

whose $_{1}$ mother paid for [[every $\left.\left[f_{2} x_{1}\right]\right]$ course $]$ ?

Here the interpretation in which the argumental variable of the $\mathrm{C}$ of every is bound is available.

Not all English speakers allow binding of pronouns by possessives, though. For example, Lasnik, 1976 judges (29) ungrammatical:

*Everyone ${ }_{1}$ 's mother thinks he ${ }_{1}$ is unfriendly

A prediction that remains to be tested is that speakers who do not allow possessives to bind pronouns should not allow them to bind $\mathrm{C}$ either. 
Importantly, then, the distribution of bound pronouns and $\mathrm{C}$ is more restricted in Chinese than in English, something we expect if the hypothesis that the argumental variable of $\mathrm{C}$ is a pronoun is correct. The (in)ability of possessives to bind variables present us with a case of cross-linguistic variation in the behavior of $\mathrm{C}$ (and maybe a case of dialectal variation in English, when further tests are conducted). The issue of variation is taken over again in $\S 4$.

\subsection{More exceptions to WCO in English}

Exceptions to WCO ((13)) in English have been noted in the literature. It is worth discussing at least some of these now because, if the argumental variable of $\mathrm{C}$ is a pronoun, we expect it to be exempt from WCO in exactly those cases in which we find that regular pronouns like he are exempt from it. I will consider two exceptions here, exemplified in (30) and (31):

(30) [who 1 [did Jan say [she admired $\left.t_{1}\right][$ in order to please him 1$\left.\left.]\right]\right]$
a. $\mathrm{PRO}_{1}$ seeing his ${ }_{1}$ father pleased [every boy $]_{1}$
b. *Mary's seeing his ${ }_{1}$ father pleased [every boy $]_{1}$

The first exception, noted by Lasnik and Stowell, 1991, is that a pronoun contained within an adjunct clause can be bound by a quantifier even if the trace of the quantifier does not c-command the pronoun. In (30), the trace of who does not c-command the pronoun him in the purpose clause, and yet the sentence has a reading in which the pronoun is bound by the quantifier.

The second exception I discuss was noted by Higginbotham, 1980: if a PRO controlled by a quantifier is present to do the binding, then the fact that the trace of the quantifier does not c-command the pronoun is irrelevant. This is the case in (31a), which allows a reading in which his varies with every boy, and (after $\mathrm{QR}$ ) the trace of every boy does not c-command his. In contrast, (31b), where there is no PRO, does not allow a bound reading of the pronoun.

Why these exceptions to the WCO generalization arise is of course an important question in its own right, but one I do not address in this paper. What is important for the hypothesis that the argumental variable of $\mathrm{C}$ is a pronoun is the prediction that $\mathrm{C}$ is also exempt from WCO in the environments in (30) and (31). This prediction seems to be borne out. Consider first (32):

(32) [Jan and John, the heads of the School of Business, asked the business professors to gather for a meeting. The meeting was about the companies with which the School of Business has close contacts. Several professors are in contact with several representatives from those companies. After the meeting, one professor asked another professor...] $\quad(\approx(16)$; cf. (30)) $[\text { Who }]_{1}$ did Jan say [she admired $t_{1}$ ] [because of how [[every [ $\left.f_{2} x_{1}\right]$ ] representative of Kodak]] treats $\operatorname{him}_{1}$ ? 
In this example, the $\mathrm{C}$ of every is embedded inside an adjunct clause, a becauseclause in this case. The $\mathrm{C}$ of every can be bound by who, despite the lack of ccommand by the trace of who.

(33a) and (33b) show that $\mathrm{C}$ is also exempt from WCO if it is bound by PRO, just as pronouns are ((31)):

(33) [The business professors, including Mary, Steve and Peter, gathered in the faculty room. The meeting was about the companies with which the School of Business has close contacts. Several professors are in contact with several representatives from those companies. After the meeting, one of the professors said...] $\quad(\approx(16)$; cf. (31)) a. $\mathrm{PRO}_{1}$ talking about $\left[\left[\right.\right.$ every $\left[\begin{array}{ll}f_{2} & \mathrm{x}_{1}\end{array}\right]$ representative of Kodak $]$ pleased [most professors $]_{1}$

b. *Mary's talking about [[every $\left.\left[f_{2} \mathrm{x}_{1}\right]\right]$ representative of Kodak] pleased [most professors $]_{1}$

(33a) has a reading in which the argumental variable of the $\mathrm{C}$ of every is bound ("most professors $\mathrm{x}$ are such that $\mathrm{x}$ 's talking about every representative of Kodak $\mathrm{x}$ has been in contact with pleased x"), even though the trace of most professors (after most professors $\mathrm{QRs}$ ) does not c-command it. (33b), on the other hand, does not have a reading in which this $\mathrm{C}$ is bound ("most professors $\mathrm{x}$ are such that Mary's talking about every representative of Kodak $x$ has been in contact with pleased x"). This is as expected.

The fact that the same exceptions to WCO that arise for pronouns arise for $\mathrm{C}$ as well is further support for the idea that $\mathrm{C}$ itself (or, rather, that the argumental variable of $\mathrm{C}$ ) is a pronoun.

\subsection{Methodology for data collection ${ }^{12}$}

The English and Chinese data presented in this chapter were collected by myself over a period of three months in 2002-2003. The consultants included three native speakers of English and two native speakers of Mandarin Chinese, For the English data, more consultants were initially considered (up to a total of seven). However, the results reported in this paper concern only three English native speakers because the remaining were either not available for questioning on a regular basis (and thus I have only partial reports from them) or they rejected bound readings of $\mathrm{C}$ in almost all cases (which prevents further testing). All of these consultants were linguists, but they were kept uninformed of the purposes of the experiment and the claims and theories being tested. Some of the judgments were collected over e-mail, others were collected in person.

Often, both for the English and the Chinese data, the judgment required concerns the availability of a reading for a sentence. To test for the availability of readings for sentences, the procedure used was as follows. A context was provided preceding the test sentence, known to be grammatical independently. The test sentence was followed by a sentence/series of sentences that were 
compatible only with one of the readings being tested. Consultants were asked whether they thought this/these last sentence(s) were compatible with the italicized sentence in the context provided. (34) and (35) illustrate this procedure for examples (7) and (9), respectively. The follow-up material is underlined:

(34) The people in our neighborhood are affiliated with a number of different charities. For example, John belongs to "Children of the World", Susan to "Children of the World" and "We are the Children", Bill to "ActionAid", Stefan to "We are the children", "ActionAid" and "PeaceNow', and so on for the other fifteen neighbors. It is customary to donate money to charities before Christmas. This year, most people have given money to every charity. There was only one neighbor who couldn't afford to give any money at all. But the economic situation has not improved so much that people were able to give money to charities they don't belong to.

(35) The business professors gathered in the faculty room. The meeting was about the companies with which the School of Business has close contacts. Several professors have had contact with several representatives from those companies lately. As it turns out, every professor admires every representative of Kodak. That is, each professor admired those representatives of Kodak that same professor has been in contact with

An affirmative answer in both of these cases was taken to indicate that the bound reading of the C of every (the every of every representative of Kodak in (9)/(35)) is available.

In order to test for the readings of a question, I elicited judgments in the following way. First, a context in which the question would be asked naturally was provided. Then the question was asked, and an answer was provided for that question. It is the answers that were crucial, for they were compatible with only one of the readings of the question. Speakers were asked whether they accepted the answer for the question in the context provided.

Consider (22) again, repeated as (36):

(36) [The students in the physics department gathered in the lounge. The meeting was about the courses they took in the spring of 2001. At the end of the meeting, the president asked...]

Mei-men kecheng dou rang shei hen laohuo?
every-CL course all make who very
'Who did every course upset?'

The context and the answer to the question were provided in English (the Chinese speakers were proficient in English). The answer provided in the case of $(22) /(36)$ in order to test whether the question in italics has a reading in which the $\mathrm{C}$ of meimen is bound ("which person $\mathrm{x}$ is such that every course that $\mathrm{x}$ took upset $\mathrm{x}$ ?") was "Peter. That is, out of all the students in the department, Peter is the one that was upset by every course that he, Peter, took". The Chinese speakers did not 
accept this as an answer for the question in italics, and the conclusion was drawn that no bound reading of the $\mathrm{C}$ of mei-men is available in $(22) /(36)$.

\subsection{General conclusions of this section}

There is evidence that the hypothesis that the argumental variable of $\mathrm{C}$ is a pronoun is correct. The evidence is that the constraints that apply to pronouns apply to $\mathrm{C}$ as well, both in Chinese and in English, even down to the exceptions to those constraints in English and to the differences between Chinese and English with respect to possessive quantifiers.

\section{Theoretical issues and consequences}

An important issue to be considered in the light of the discoveries in $\S 3$ is the syntactic presence of $\mathrm{C}$, which I promised to come back to anyway.

It might be tempting to take the evidence that $\mathrm{C}$ is subject to $\mathrm{WCO}$ as evidence for the position that $\mathrm{C}$ is present in the syntax. If WCO is a syntactic constraint, how could it be otherwise? The thing is that WCO does not have to be a syntactic constraint. In fact, there are proposals of non-syntactic versions of WCO in the literature, such as Jacobson (2000). Of course, Jacobson's general assumptions about matters such as the organization of the grammar or about the very existence of variables are radically different from the assumptions I make here. We could say that, if one assumes the existence of variables in the grammar and a syntactic version of $\mathrm{WCO}$, then the data from $\S 3$ shows that $\mathrm{C}$ is an item present in the syntax ${ }^{13}$. This is in opposition to Stanley (2000), who takes the fact that certain contextual variables (different from $\mathrm{C}$ ) are subject to $\mathrm{WCO}$ as evidence that they are syntactically active.

Contra Recanati (2002), the evidence in $\S 3$ shows that $\mathrm{C}$ is a linguistically active variable (that is, a variable that is present at some level of linguistic representation). Whether WCO is a syntactic or a semantic constraint, it is clearly a linguistic constraint. Recanati's (2002) suggestion for a non-linguistic (i.e., nonsyntactic and non-semantic) treatment of contextual variables like $\mathrm{C}$ is thus not appropriate $^{14}$.

What can also be said in favor of the position that $\mathrm{C}$ is present syntactically is that if $\mathrm{C}$ is a pronoun, which I have shown to be the case here, and pronouns are present in the syntax, which I take to be uncontroversial, then $\mathrm{C}$ should be present in the syntax as well ${ }^{15}$.

What sorts of evidence could one bring up against the idea that $\mathrm{C}$ is pronoun? Cappelen and Lepore (2002) bring up a number of problems for the idea that contextual variables are pronominal items. A posited covert pronoun should enter into anaphoric relations, since pronouns can. For example, $\mathrm{C}$ should be able to antecede other pronouns, since pronouns can antecede other pronouns, as shown by he/him in (37) (modified): 
But $\mathrm{C}$ cannot antecede pronouns:

*Many students failed, and it is a big domain

If the potential covert pronoun is made overt, the relationship with it can be established though:

(39) Many students in this domain failed, and it is a big domain

Under the hypothesis that $\mathrm{C}$ is a covert pronominal item, we expect parallel behavior with other pronouns, but that is not what we find in examples like (37)(38).

Notice, though, that not all pronominal elements can antecede pronouns. Consider the following facts from Spanish:

a. ${ }^{*}$ pro $_{1}$ dijo que vendría pronto y él $1_{1}$ también dijo que traería said that would-come early and he also said that would-bring

a Manuela

to Manuela

'He said that he would come early and he also said that he would bring Manuela'

b. Él dijo que vendría pronto y él $l_{1}$ también dijo que traería a Manuela

(40b) needs a context in which an appropriate reason is provided for the presence of the pronoun in the second clause. Such a context would be one in which the speaker is angry because two things didn't happen: whoever said that he would arrive early didn't, and that same person, who said that he would bring Manuela, didn't do so either. The speaker feels that it is important to emphasize the two faults committed by this person, and can do so by repeating the pronoun. The first pronoun in (40b) can antecede the second one in this context. In the same context, however, pro cannot antecede the pronoun in the second clause in (40a). A context in which (40a) is felicitous, though without coreference between pro and $e ́ l$, is one in which Juan arrived late and the person, different from Juan, who had to bring Manuela didn't. The speaker points to the person who had to bring Manuela and didn't when s/he says él. If not all pronominal elements can antecede pronouns, the behavior of $\mathrm{C}$ in (38) is not surprising.

Also, as Andy Kehler (p.c.) points out, (38) improves when an antecedent for $\mathrm{C}$ is provided in previous context:

(41) Math is a very complicated subject. Many students fail; it is a big domain, after all.

In (41), many quantifies over the set of Math students. The restriction to individuals who study Math is provided by the preceding context. It can be 
dependent on $\mathrm{C}$ in this example. Notice that (37) and (40b) are also appropriate only if there is a reference for the pronoun helél.

Facts like (37) and (40) suggest that pronominal items sometimes can and sometimes can't antecede other pronominal items. This suggests that the ability of pronouns to depend anaphorically on some item is not really indicative of the nature (pronominal or not) of the item ${ }^{16}$. Hence, (38) is not indication that $\mathrm{C}$ is not a pronoun. What seems to be wrong with the example is that a referent for $\mathrm{C}$ must be provided, as suggested by Kehler's example $((41))^{17}$.

The results reported in $\S 3$ need to be evaluated from the point of view of language acquisition. Given that there is variation in the distribution of pronouns across languages (or, at least, across English and Chinese), we are forced to postulate a parameter about binding by possessive quantifiers. This parameter allows binding by such items in English but not in Chinese (with qualifications, having to do with potential dialectal variation in English, as we have seen). That $\mathrm{C}$ is covered under the umbrella of this parameter constitutes further support for the hypothesis pursued here, that $\mathrm{C}$ is a pronoun. This is because if $\mathrm{C}$ is a pronoun, the task of language acquisition is made easier on the child, in the sense that the English child needs exposure to a limited set of data only, not even necessarily related to $\mathrm{C}$ (which, arguably, are more complicated than the data with pronouns such as he), in order to draw the conclusion that $\mathrm{C}$ can be bound by possessive quantifiers. Likewise, once the Chinese child has drawn conclusions about the behavior of pronouns with respect to binding by possessive quantifiers, he does not need to be exposed to further data with $\mathrm{C}$.

An important issue that arises in this discussion is how exactly the child, whether a speaker of Chinese or English, learns the behavior of pronouns with respect to binding by possessive quantifiers. Notice for example the difficulty of the English child learning the behavior of pronouns: what he or she has to learn is not that a sentence is possible, but that a reading is possible. Significantly, the Chinese child has to learn, not that a sentence is impossible, but, again, that a reading is impossible. One possibility here is to say that the initial assumption made by the child is that readings in which a pronoun is bound by a possessive quantifier are impossible, and only in case the child is provided with positive evidence does he or she change the assumption. This possibility hinges, of course, on the availability of a certain amount of input for the child.

I leave the discussion about language acquisition here, noting that whatever its outcome turns out to be (and here I appeal to the experts), it is always advantageous to be able to say that $\mathrm{C}$ is a pronoun. Whatever language acquisition mechanisms turn out to be the correct ones, in particular for the acquisition of binding by possessive quantifiers, learning the behavior of $\mathrm{C}$ will never come at an extra cost.

\section{Conclusion}

In this paper I have provided evidence that the argumental variable of $\mathrm{C}$ is a pronominal item. I have shown that the behavior of the bound argumental variable 
of $\mathrm{C}$ is parallel to the behavior of bound regular pronouns such as he, in several interesting respects. First, $\mathrm{C}$ is subject to WCO in English and Chinese. Then, exceptions to WCO in English arise both for pronouns and for $\mathrm{C}$. Then, where the distribution of bound pronouns is more restricted (as in Chinese vs. English with respect to binding by possessive quantifiers), the distribution of bound $\mathrm{C}$ is equally more restricted.

Some consequences of this discussion for the syntactic presence of $\mathrm{C}$ and for language acquisition were briefly discussed.

\section{Endnotes}

${ }^{*}$ This paper presents material from Chapter 2 of my dissertation (Martí (2003)). Thanks to the audiences at SALT XIII and at the Annual Conference of the Linguistic Society of Southern Africa (2003), specially Richard Breheny, Andy Kehler, Jochen Zeller, Angelika Kratzer and Chris Barker, for their comments and questions. And thanks to Norman Clarke, for being my friend and for providing a place for us to stay in Seattle.

${ }^{1}$ For discussion of free instances of $\mathrm{C}$ within the framework of this hypothesis, see Martí (2003).

${ }^{2}$ It is not the only way, though. See von Fintel (1994: 28-9), Neale (1990: 95102), Stanley and Szabó (2000) and Stanley and Williamson (1995) for discussion of some possibilities and arguments that a device that interacts with the recursive semantics is needed. See also Breheny (this volume).

${ }^{3}$ I will often abbreviate "argumental variable of C" to just " $C$ ".

${ }^{4}$ See Stanley (2002) for examples where the functional variable of $\mathrm{C}$ is bound.

${ }^{5}$ In (1), the functional variable can be treated as the identity function and the argumental variable as a set of individuals (Stanley, 2000 \& 2002), or C can be a simple variable, a set of individuals.

${ }^{6}$ Pauline Jacobson (p.c.) suggested this possibility to me.

7 Student is a relational noun according to Barker and Dowty's tests because the prenominal possessive (John's students) and the of-possessive (the students of John) are possible and have the same meaning.

${ }^{8}$ Both the prenominal possessive (John's charity) and the of-possessive (the charity of John) are possible with charity. However, it is not possible to interpret charity as "non-profit organization" in the of-possessive, which is the sense intended in the text. Charity is thus non-relational when understood as "non-profit organization", though possibly relational when understood as "charitable qualities".

${ }^{9}$ Representative is a relational noun, since both Kodak's representative and the representative of Kodak are possible with the same meaning, the meaning intended in the text.

Observe that the bound readings in (7) and (9) need context to make a function salient for $\mathrm{f}$, whereas the bound reading of (2) doesn't. I hypothesize that the reason for that is that, in (2), the relational noun itself makes a value for the 
function salient, but (7) and (9) have no relational noun that can do that and have to rely on the context.

${ }^{10}$ And the if-clause, if it rained, provides the first argument (or, in my analysis, the second) of the adverb of quantification, as widely assumed.

${ }^{11}$ An interesting question is whether the facts I present below are compatible with any version of WCO, as suggested by Howard Lasnik (p.c.). I leave this question aside here.

${ }^{12}$ This section was inspired by $\S 3.2$ in Matthewson (1998).

13 It remains to be seen in detail whether a system like Jacobson's could accommodate the fact that $\mathrm{C}$ is subject to WCO. I leave that for a future occasion.

14 It is unclear how such a treatment would deal with the binding of these variables to begin with.

${ }^{15}$ Partee (1989) has suggested that contextual variables associated with items like opposite or local are not syntactically present. Her arguments together with answers to them are discussed in Martí (ms.) and in Chapter 2 in Martí (2003).

${ }^{16}$ In any case, why should it be?

17 Other arguments from Cappelen and Lepore are against $\mathrm{C}$ being an indexical like $I$ or here, which I am not advocating.

\section{References}

BARKer, Chris and Dowty, DAVID. 1992. Non-verbal Thematic Proto-Roles. Proceedings of NELS 23.

BREHENY, RICHARD (this volume) A Lexicalist Account of Implicit (Bound) Contextual Dependence

CAPPelen, Herman and LePore, Ernie. 2002. Indexicality, Binding, Anaphora and $a$ priori Truth. Analysis, 62.271-81.

ChIERChiA, GenNARo. 1993. Questions with Quantifiers. Natural Language Semantics, 1.181-234.

-. 1995. Dynamics of Meaning: Anaphora, Presupposition, and the Theory of Grammar. Chicago: University of Chicago Press.

Chomsky, Noam. 1976. Conditions on Rules of Grammar. Linguistic Analysis, 2.303-51.

COOPER, RoBIN. 1996. The Role of Situations in Generalized Quantifiers. The Handbook of Contemporary Semantic Theory, ed. by Shalom Lappin, 6586. Oxford: Blackwell Press.

Elbourne, PAUl. 2002. Situations and Individuals, MIT: Ph.D. dissertation.

ENGDAHL, ElisabeTH. 1986. Constituent Questions -The Syntax and Semantics of Questions with Special Reference to Swedish. Dordrecht, Boston, Lancaster, Tokyo: Reidel.

VON FINTEL, KAI. 1994. Restrictions on Quantifier Domains, University of Massachusetts: Ph.D. dissertation.

- 1995. A Minimal Theory of Adverbial Quantification. Context Dependence in the Analysis of Linguistic Meaning, Prague and Bad Teinach. 
HeIM, IRENE. 1990. E-type Pronouns and Donkey Anaphora. Linguistics and Philosophy, 13.137-77.

-. 1991. Artikel und Definitheit/Articles and Definiteness. Semantik: Ein internationales Handbuch der zeitgenössischen Forschung, ed. by Arnim von Stechow and Dieter Wunderlich. Berlin: Walter de Gruyter.

Higginbotham, James. 1980. Pronouns and Bound Variables. Linguistic Inquiry, 11.679-708.

HuANG, C.-T. JAMES. 1982. Logical Relations in Chinese and the Theory of Grammar, MIT: Ph.D. dissertation.

JaCOBSON, PAUline. 2000. Paycheck Pronouns, Bach-Peters Sentences, and Variable-free Semantics. Natural Language Semantics, 8.77-155.

Koopman, Hilda and Sportiche, DominiQue. 1983. Variables and the Bijection Principle. The Linguistic Review, 2.139-60.

LASNIK, HOWARD. 1976. Remarks on Coreference. Linguistic Analysis, 2.1-22.

LASNIK, HowARD and StOWEll, TIM. 1991. Weakest Crossover. Linguistic Inquiry, 22.687-720.

LIN, Jo-WANG. 1998. Distributivity in Chinese and its Implications. Natural Language Semantics, 6.201-43.

MARTí, LuISA. 2003. Contextual Variables. University of Connecticut: PhD. dissertation. Available at www.languages.wits.ac.za/ marti

- ms. The Syntactic Presence of Contextual Variables. Available at www.languages.wits.ac.za/ marti

MAtTHEwSON, LISA. 1998. On the Interpretation of Wide-Scope Indefinites. Natural Language Semantics, 7.79-134.

Neale, Stephen. 1990. Descriptions. Cambridge, MA: MIT Press.

PARTEE, BARBARA. 1989. Binding Implicit Variables in Quantified Contexts. Papers from the Regional Meetings, Chicago Linguistic Society.

Pelletier, Francis J. 2003. Context Dependence and Compositionality. Mind and Language, 18.148-62.

Postal, Paul M. 1971. Cross-over phenomena. New York: Holt, Rinehart, and Winston.

RECANATI, FRANÇOIS. 2002. Unarticulated Constituents. Linguistics and Philosophy, 25.299-345.

Stanley, Jason. 2000. Context and Logical Form. Linguistics and Philosophy, 23.391-434.

-. 2002. Nominal Restriction. Logical Form and Language, ed. by G. Peters and G. Preyer, 365-88. Oxford: Oxford University Press.

Stanley, Jason and SZabo, Zoltan. 2000. On Quantifier Domain Restriction. Mind and Language, 15.219-61.

StANLEY, JASON and Williamson, Timothy. 1995. Quantifiers and Context Dependence. Analysis 55:291-95.

WAsow, ThOMAS. 1972. Anaphoric relations in English, MIT: Doctoral dissertation. 
WesterstÅHL, DAg. 1985. Determiners and Context Sets. Generalized Quantifiers in Natural Language, ed. by Johan van Benthem and Alice ter Meulen, 47-71. Dordrecht: Foris. 